\title{
Internacionalidad, Higiene y Cuestión Social en Buenos Aires (1850-1910). Tres momentos históricos
}

por

\author{
Ricardo González Leandri
}

Grupo de Estudios Americanos. Instituto de Historia-CCHS, CSIC

\begin{abstract}
A través de tres momentos históricos este artículo analiza aspectos de la circulación internacional de expertos, conocimientos y modelos institucionales que vincularon a la Higiene con la Cuestión Social en Argentina en el siglo XIX y principios del XX. Resalta la gran movilidad a la vez que el eclecticismo temprano y permanente con los que se formaron redes $y$ se incorporaron conocimientos.
\end{abstract}

Palabras Clave: Cuestión social; Estado; Higiene; Internacionalidad; Salud; Asistencia; Médicos; Argentina.

\section{INTRODUCCIÓN $^{1}$}

Entre 1850 y 1890 emergió en Buenos Aires una «cuestión social temprana» que se caracterizó por la paulatina diferenciación del tronco de la beneficencia y la caridad de áreas más específicas de «intervención social», orientadas tanto desde sectores de la sociedad civil, que planteaban nuevos mecanismos de colaboración y protección, como desde las autoridades pú-

\footnotetext{
${ }^{1}$ Este artículo, que contó con la colaboración de María Belén Irazábal, es uno de los resultados del Proyecto de Investigación «Circulación internacional de saberes y prácticas institucionales en la consolidación del Estado Social en Argentina» HAR 2009-13555, financiado por el programa I+D del Ministerio de Economía y Competitividad del gobierno de España. Agradezco los comentarios de Pilar González Bernaldo de Quirós, Juan Suriano, Mirian Galante y Elda González.
} 
blicas $^{2}$. Hacia fines de siglo otras ansiedades, producto de la emergencia de un nuevo conflicto social vinculado sobre todo a los efectos de la inmigración masiva y de conflictos de raíz laboral, denotarían la emergencia de una «moderna cuestión social». Uno de los ejes vinculantes entre ambas fue el «descubrimiento» de la salud como problema social, que se dio a través de la paulatina consolidación de la idea de prevención, el fomento de lazos de interdependencia social y la creación de bienes colectivos ${ }^{3}$. Se trata de una cuestión que ha recibido bastante atención reciente por parte de la historiografía. Sin embargo, en un país como la Argentina paradójicamente, caracterizado por su fuerte apertura al mundo, algunos de los rasgos de la internacionalidad de ese proceso han sido en general poco destacados ${ }^{4}$. En este artículo analizaremos tres momentos que hacen referencia a algunos rasgos de esa relación internacional entre Higiene y Cuestión Social.

\section{Higiene, Cuestión Social y cosmopolitismo temprano}

Los legados sociales y políticos europeos del siglo XVIII, como el auge comercial y la industrialización, hicieron más visibles las contradicciones y desigualdades sociales de esa nueva modernidad en el siglo XIX. Críticos como Villermé observaron que nuevos fenómenos como el pauperismo podían poner en peligro el propio sistema social ${ }^{5}$. La irrupción del cólera en Europa agudizó la preocupación por la salud de la población y su incidencia sobre la cohesión social ${ }^{6}$. Asociada a los grandes movimientos humanos, su propagación permitió constatar la fuerza de la interdependencia mundial y de sus efectos no deseados ${ }^{7}$. Se ha escrito que para entonces comenzó a darse una «unificación del mundo por la enfermedad», precisamente para la misma época en que se realizó la Ex-

\footnotetext{
2 González Leandri, González Bernaldo de Quirós y Suriano, 2010. González Leandri, 1984: 251-258. González Bernaldo de Quirós 2001: 123-157. Moreno, 2000.

3 González Leandri, 1999; 2012: 125-158. Armus, 2000: 507-561.

4 González Leandri, 1999. Armus, 2000: 507-561. Recalde, 1997. Belmartino, 1987; 1988; 2005. Salessi, 1995. Di Liscia, 2002.

5 Donzelot, 2007. Castel, 1997.

${ }_{6}^{6}$ Aisenberg, 1999. Baldwin, 1999. Rosenberg, 1999.

${ }^{7}$ Las pandemias de cólera del siglo XIX fueron cinco: la primera, entre 1817 y 1823 ; la segunda, entre 1826 y 1837; la tercera, entre 1840 y 1859; la cuarta, de 1863 a 1875 ; y la quinta, entre 1883 y 1892. Harrison, 2006: 197-217. Huber, 2006: 453-476.
} 
posición Universal de Londres, en la que se ha querido ver el nacimiento de un nuevo «internacionalismo» ${ }^{8}$.

Hacia 1820 y 1830 se consolidó la idea de que el agente difusor de la enfermedad eran los miasmas ${ }^{9}$. Su cristalización como concepto y su naturalización como realidad cultural hizo que se prestara una atención renovada a las condiciones de vida de los pobres, a los efectos no deseables de la urbanización, a la falta de sanidad y a la superpoblación de algunos distritos. Esto impulsó, en estrecha relación con procesos sociales y políticos específicos de cada país o grupo de países, el afianzamiento y circulación por toda Europa y su proyección a otros continentes de la corriente higienista o sanitarista, enraizada en el iluminismo y en teorías posteriores de Villermé ${ }^{10}$. Gran Bretaña sumó con el tiempo un importante desarrollo práctico en mejoras urbanas y reforma higiénica, y un sentido clásico de reforma ambiental a través de expertos, de filiación benthamista, como Chadwick, Southwood Smith y John Simon ${ }^{11}$.

Peter Baldwin, en su libro sobre el contagio y el Estado en Europa, señala la propia trayectoria del cólera y la distancia temporal entre sus escalas como facilitadora de cambios en los estilos de gobierno. De tal forma, países como Suecia, Francia y Gran Bretaña, no afectados por los primeros brotes epidémicos, habrían logrado según esta hipótesis acumular experiencia a partir de los casos iniciales, lo que les habría permitido "aprender a ser liberales» ${ }^{12}$. Resulta muy sugerente hacerse la pregunta sobre cómo esa learning curve, señalada por Baldwin, afectó a países como la Argentina, con realidades y cuestiones sociales bien diferentes y más distantes, al menos en apariencia,

\footnotetext{
${ }^{8}$ En el periodo que nos ocupa tuvieron lugar las conferencias de París en 1851 y 1859, a la que asistieron sólo diplomáticos; una tercera, en Constantinopla, justo después de la cuarta epidemia de cólera en Europa; una cuarta, en Viena, después de la epidemia de 1873. La quinta conferencia tuvo lugar en Roma en 1884, a la que asistió por primera vez la Argentina. Se realizaron también una serie de Congresos Internacionales de Higiene que tuvieron un carácter menos oficial y más científico y cuyo fin fue sugerir medidas y no llegar a acuerdos o convenios que obligara a los países. Estos tuvieron lugar en Bélgica en 1851, 1852 y 1875; en París, en 1878; en Turín, en 1880; en Génova, en 1882; en La Haya, en 1884; en Viena, 1887, y nuevamente en París en 1889. Huber, 2006: 453-476.

9 Se pensaba que podía tratarse de partículas en suspensión en el aire, en las aguas estancadas y en las aglomeraciones humanas. Se especulaba también que los miasmas podían ser, o contener, pequeños organismos vivos de carácter microscópico. Conocidos ya desde el siglo anterior, la ambigüedad con que eran descriptos y definidos los convirtió en un concepto flexible apto tanto para contagionistas como anticontagionistas. Fue precisamente esto lo que impulsó su popularidad y su conversión en una realidad cultural de primer orden a nivel internacional durante la mayor parte del siglo XIX. Baldwin 1999: 37-122.

${ }^{10}$ Cipolla, 1992. Latour, 1988. Ackerknecht, 1948: 117-155.

${ }^{11}$ Baldwin, 1999: 6.

12 Ibidem: 1-36.
} 
de los circuitos principales de circulación de las miasmas y de las ideas y prácticas higiénicas que pretendían luchar contra ellos ${ }^{13}$.

La ciudad de Buenos Aires se mantuvo ajena durante la primera mitad del siglo XIX a las oleadas de cólera que mantuvieron en vilo a los gobiernos europeos. Sin embargo, se vio afectada de manera indirecta: las noticias de viajeros, inmigrantes, diplomáticos y comerciantes daban cuenta de esos sucesos, y generaron un clima de alerta en el medio urbano. Con respecto a las ideas la distancia se redujo, además, por la movilidad de una serie de expertos (médicos, químicos, ingenieros, farmacéuticos) europeos que llegaron por goteo durante esos años al Río de La Plata ${ }^{14}$.

Si bien en los años 20 se registraron en Buenos Aires unos primeros esbozos de saneamiento urbano sistemático, orientados según ideales benthamitas, fue recién en los años 50, con la creación de la Municipalidad y el Consejo de Higiene, cuando comenzaron a observarse estrategias sanitarias más definidas. Varios de los médicos y químicos que desarrollaron su labor en la región durante esos años de mediados de siglo habían sido actores en epidemias en ciudades y regiones europeas, como Barcelona, Vigo, Manchester, Liguria, e incluso en la India. A través de ellos, los miasmas ya estaban presentes antes de que se hicieran sentir como una cuestión crítica ${ }^{15}$.

Las epidemias comenzaron a arreciar con fuerza esporádica en Buenos Aires a partir de 1856. Fue sin embargo en 1867 cuando, como parte de la cuarta pandemia internacional, el cólera se instaló en Buenos Aires con amplias consecuencias sociales e institucionales. Entre esos dos momentos comenzó a hablarse de Higiene de una manera más sistemática ${ }^{16}$. Durante esos años se hizo notoria la presencia de un pequeño grupo de «especialistas» - en el cual se destacaban los químico-farmacéuticos Miguel Puiggari (catalán) y Charles Murray (natural de Manchester), que discutían sobre distintas concepciones de «Higiene pública» a tono con circuitos de ideas más amplios- ${ }^{17}$.

13 Ibidem: 10-36. González Leandri: en prensa.

${ }^{14}$ La guerra y posteriormente la construcción institucional y de infraestructuras ofrecían importantes perspectivas a aquellos con conocimientos específicos. García Belsunce, 1977. González Bernaldo de Quirós, 2007.

15 Kohn Loncarica, 1981. González Bernaldo de Quirós, González Leandri y Suriano, 2010.

16 González Leandri, 1999.

17 La Revista Farmacéutica actuó como importante plataforma. Pronto se sumaron algunos médicos locales, que se agruparon alrededor de la Revista Médico Quirúrgica, entre los que destacó Pedro Mallo. Proponían emular al Consejo de Salubridad de París y seguir las recomendaciones de la conferencia de Higiene de Bruselas. Consejo de Redacción, 1/2 (23 de abril de 1864): 21; Consejo de Redacción, $1 / 3$ (8 de mayo de 1864): 38. Puiggari, 2/1 (8 de abril de 1865): 2. 
Miguel Puiggari, uno de los impulsores de la sociedad Nacional de Farmacia, fue la figura más relevante. Oriundo de Barcelona, donde realizó sus estudios, arribó al país en 1851. Al poco tiempo estableció vínculos con las elites locales, lo que le permitió emprender un viaje a Francia y España, comisionado por el gobierno de la provincia de Buenos Aires con el objetivo de afianzar contactos académicos. Como consecuencia se generó un circuito de información y lazos intelectuales cuyo rastro se hizo evidente con motivo de la publicación de su libro Lecciones de Química aplicada a la Higiene y la Administración ${ }^{18}$.

Desde el punto de vista académico, las Lecciones actuaron como un corpus que, dado su carácter fundacional y sus propuestas de aplicación, orientó las formas de la selección, adaptación y reformulación de las experiencias y conocimientos químicos e higiénicos de otras realidades nacionales al ámbito local. Uno de sus objetivos principales fue difundir y promover en el medio porteño y bonaerense las sugerencias de las Conferencias Sanitarias Internacionales $\mathrm{y}$, sobre todo, del Congreso de Higiene de Bruselas ${ }^{19}$. La estructura narrativa del libro giró alrededor del concepto de «exhalaciones miasmáticas», para cuya definición Puiggari se valió de criterios esbozados por Liebig y Muñoz de Luna, y de las experiencias de Peclet, Dumas y Gavaret, citadas a través de Tardieu $^{20}$. Si bien cita como autoridades relevantes a Tardieu y Liebig ${ }^{21}$, se menciona de manera especial a algunos químicos e higienistas españoles. Proliferan las citas a Orfila (Mateo Buenaventura) y destaca la mención elogiosa y hasta amistosa de Muñoz de Luna (Torres Muñoz de Luna). Importante es la referencia a Felipe Monlau, a quien cita con frecuencia en temas de política higiénica, sobre todo en el apartado referido a hospitales, casas de beneficencia y sanidad ${ }^{22}$. Dichos autores son considerados artífices para esta época de la «europeización y profesionalización» de la química y la higiene españolas ${ }^{23}$. Pedro Felipe Monlau y Roca participó de manera activa en las redes de expertos que se estaban conformando a través de toda Europa con

18 Tales lazos se detectan tanto en la Revista Farmacéutica de Buenos Aires como en las del Restaurador Farmacéutico de Madrid, en el que se destacaron los comentarios del higienista español Felipe Monlau. Puiggari, 1863. Consejo de redacción, 1/11 (8 de septiembre de 1864): 175-177.

19 Puiggari, 1863.

${ }^{20}$ Ibidem: 43-47.

${ }^{21}$ Ibidem: 19.

22 Orfila (Mateo Buenaventura), destacado químico español nacido en Mahón y exiliado en Francia, donde escribió casi toda su obra. Ibidem: 162-163.

${ }^{23}$ Se señala la influencia de los estudios de Muñoz de Luna en Alemania y su papel como traductor y difusor de la obra de Liebig al castellano. Portela y Soler, 1992: 85-107. 
las conferencias y congresos sanitarios internacionales, a los que asistió como representante español (París, 1851 y 1859; Constantinopla, 1866) ${ }^{24}$. El mapa de ese proceso de circulaciones y construcción de pequeñas redes de difusión y recreación de conocimientos higiénicos se enriqueció con otras trayectorias e influencias. La mirada local, fuertemente internacionalizada, propia de la década de 1860 , se conformó a través de una trama de debates e informaciones y recomendaciones internacionales que tuvieron como protagonistas a una amplia gama de personajes de muy diversa procedencia y tradición personal y académica. En esa trama de circulación destacaron químicos inmigrantes, como Puiggari o Murray, pronto convertidos en figuras locales notables, que contribuyeron a consolidar un ámbito de debate sobre Higiene a partir de los contactos internacionales que incorporaban como parte de su bagaje inmigratorio y de aquellos que tejieron como consecuencia de su actividad local. También lo hicieron hijos de inmigrantes con trayectoria pública y funcionarial consolidada en etapas anteriores, como Antonio Wilde, que desde su actividad polifacética como médico y funcionario educativo contribuyó a difundir y «naturalizar» conocimientos que circulaban a escala internacional, y médicos extranjeros, activos y con propuestas innovadoras. Dichas propuestas estaban inspiradas en Southwood Smith y otros sanitaristas británicos, tales como John Scribener, o Thomas Huchkinson, de paso por el país, pero con notable actividad previa en epidemias en Inglaterra, Irlanda y la India ${ }^{25}$.

El optimismo sanitarista basado en la teoría miasmática «atmosférica», a la que se adhería la mayoría de quienes escribían en la prensa política, fue tratado sin embargo con un poco más de escepticismo por un sector del campo académico local ${ }^{26}$. El ejemplo más nítido fue una serie de artículos publicados en la Revista Médico Quirúgica, con el título de «El eclecticismo en Medicina», por Juan Ángel Golfarini. Mostraba Golfarini un amplio conocimiento de las ideas sanitarias en boga a nivel internacional que lo llevó a enfatizar la falta de respuestas de la ciencia a los problemas higiénicos y epidémicos

${ }^{24}$ Es considerado uno de los artífices clave de la consolidación en el siglo XIX de la Higiene Científica en España. Reformador y político, su exilio en Francia lo puso en contacto el movimiento higienista francés. Es conocido su vínculo con Sutherland, Bo, Mantegazza, Betti y otros intelectuales y sanitaristas. Se convirtió también en un importante difusor de la Higiene a través de obras como Elementos de Higiene Privada (Barcelona, 1846 y 1857) y Elementos de Higiene Pública (Barcelona, 1862), que tuvieron varias reediciones y fueron utilizadas como manuales en distintas facultades, incluso la de Buenos Aires, durante buena parte del siglo XIX. Grangel, 1983. Alcalde González, 1999, s/n.

25 Roncagliolo, 1858. Recalde. 1993. Hutchinson, 1864. Scrivener, 1868. Wide, 1868.

${ }^{26}$ González Leandri, 1999; 2012: 125-131. González Leandri, González Bernaldo de Quirós y Suriano, 2010: 31-86. 
del momento ${ }^{27}$. La serie representa, por tanto, un importante indicio del tipo de información que poseían los médicos jóvenes nativos y la forma en que esta circulaba: los autores mencionados eran en su gran mayoría franceses; en cambio, en las citas al pie de página, en las que se señalaba el lugar de publicación, predominaban los españoles, de Madrid y Barcelona ${ }^{28}$. Golfarini llegó a la conclusión de que los conceptos clave que enmarcaban el debate higiénico eran por un lado los de contagio y «transmisibilidad»y, por otro el de Higiene, pública y privada, en la que depositaba su confianza como herramienta imprescindible. Recomendaba la adopción de una postura ecléctica en cuestiones de higiene pública.

El eclecticismo de Golfarini fue producto de una mirada que cuestionaba simultáneamente a la elite médica local y los usos superficiales que se hacían de ejemplos de otros países y regiones. Proponía cambios en la práctica médica y una higiene pública que combinara la experiencia internacional con un mayor énfasis en lo que llamaba «observación bien orientada» ${ }^{29}$.

Podría decirse que, como fruto de esa peculiar trama circulatoria de la década de 1860-1870, los rasgos centrales, y casi todos los temas fundamentales, de una concepción o programa higienista, que se institucionalizaría y «nacionalizaría» a fines de los 70 y en la década de 1880 , ya estaban presentes

27 Golfarini, 1867: 195-202.

${ }^{28}$ Las obras citadas a pie de página con algún tipo de referencia a la editorial o al lugar de publicación fueron (se citan en primer lugar las referencias según aparecen en las fuentes, y entre paréntesis dichas referencias corregidas): Alfaro N., Tratado del cólera morbus (Barcelona año de 1932), (Alfaro, N., Tratado de cólera Morbo redactado especialmente con presencia de las observaciones recogidas en los hospitales de Paris durante la epidemia que ha afligido a esta capital, Barcelona, Imprenta Bergnes, 1832); Drument J., Memoria sobre el cólera morbus (Barcelona año 1834), (Drument, J., Memoria sobre el cólera morbo según observaciones escrupulosamente hechas en Francia y Portugal por el profesor en medicina el Dr. Juan Drument, Barcelona, Imprenta de A. Bergnes y Cía. 1834); Torrecilla V., Historia de la epidemia de cólera morbus de París en 1832 (Madrid, 1833), (Victoriano Torrecilla, Historia de la epidemia de cólera-Morbo de París en 1832 y consideraciones generales sobre esta enfermedad, Madrid, Ibarra, 1833); Jahr, Tratamiento homeopático del cólera (Barcelona, 1853), (Gootlieb Heindrich Georg Jahr, Nueva farmacopea homeopática o historia natural y preparación de los medicamentos homeopáticos, Boix, Madrid, 1847). Sin referencia editorial ni lugar de edición se menciona a: Enciclopedia Francesa; Rouchoux, Notice sur le Cholera morbus; Trousseaux, Patología interna; Fabre, Biblioteca del médico práctico. Cita también los nombres de Magendié Delpech, Brussais, Orlon y Barbier, pero sin referencias específicas. Golfarini, 1869: 42-43.

${ }^{29}$ Afirmaba Golfarini: «Emulemos a la gran república del Norte, y disputemos la palma en todas las esferas de la actividad humana, pero amemos la propia personalidad como los atrevidos yankees, aplaudamos y veneremos como ellos la iniciativa intelectual, adoremos como ellos el trabajo que oculta tesoros vedados y envolvámonos con el manto vivificante de la libertad». Ibidem: 196. 
en el medio local, aunque evidentemente con menor nivel de desarrollo y difusión. Se trató de una visión en la que no era tan importante la causa precisa de la enfermedad, o de los cuerpos o partículas que la transmitían, sino la fe en que determinados procedimientos, caracterizados como «preventivos»y portadores de civilización, podían atenuarla Dicho ideario higiénico tampoco se vio alterado de manera significativa por la introducción posterior de procedimientos bacteriológicos, sólo se ampliaron los recursos y se sofisticaron los procedimientos.

El énfasis casi exclusivo que la historiografía ha puesto en aspectos, sin duda importantes, vinculados a la construcción institucional y al papel de «pioneros» jugado en las décadas de 1870 y 1880 por médicos locales como Guillermo Rawson, Eduardo Wilde y Pedro Mallo, entre otros, ha oscurecido la riqueza del haz de circulaciones de saberes y prácticas internacionales y locales del que inevitablemente participaban y del que eran consecuencia ${ }^{30}$. Poco se habla por ejemplo de la notable influencia de los trabajos de Puiggari y Monlau sobre las lecciones de higiene de aquellos tres médicos y la de los médicos neobenthamitas que circulaban por Buenos Aires sobre algunos juicios vertidos por Wilde acerca del vínculo entre higiene y política pública. La no observancia de sus diálogos, influencias y préstamos con respecto a la trama circulatoria descrita, también los ha empobrecido paradójicamente como personajes históricos. En esto habrá que seguir avanzando.

\section{Los años 80, el progreso y los «retornos» del joven Coni}

Los últimos años de la década de 1870 y, sobre todo, los años 80 marcaron un punto de inflexión importante en la historia argentina. A la consolidación definitiva del estado nacional se sumaron el inicio de una mayor estabilidad política y un crecimiento económico sin precedentes. El lema «Paz y administración» ilustró muy bien aquella voluntad institucional a la que también se plegaron los médicos como corporación naciente ${ }^{31}$. La modernización del país — que a partir de entonces se aceleró — trajo aparejadas nuevas realidades. Se iniciaba una era de progreso que presentaba a su vez problemas derivados sobre todo del arribo masivo de inmigrantes, la transformación urbana y una incipiente industrialización en un contexto internacional crecientemente globalizado por la lógica del capitalismo ${ }^{32}$.

\footnotetext{
30 Rawson, 1876; 1942. Wilde, 1885. Mallo, 1878.

31 Scobie, 1977. Ferrari y Gallo, 1980. Botana y Gallo, 1997. Lobato, 2000.

32 Zimmermann, 1995: 41-109. Suriano, 2000: 1-29.
} 
No puede hablarse durante este periodo de circulación de saberes y prácticas institucionales sin hacer referencia a Emilio Coni, el médico argentino que más vínculos ha establecido con ámbitos académicos y de reforma social europeos y latinoamericanos ${ }^{33}$. De origen francés, su fluido manejo del idioma que con orgullo proclamaba como el lenguaje internacional de la ciencia, le permitió durante esos años actuar como una auténtica «bisagra» intelectual entre ámbitos internacionales y locales, fundamentalmente el Estado y el campo médico y el filantrópico, pero también la municipalidad de Buenos Aires y gobiernos provinciales.

A pesar de que su paso por cargos institucionales de importancia fue breve - como miembro por ejemplo de la Comisión Municipal en 1880 y director de la Asistencia Pública en 1890-, Coni fue un activo partícipe de la construcción burocrático administrativa que convirtió a la Higiene, pero sobre todo al accounting sanitario/estadístico, en estrategias primordiales para definir la salud como un fenómeno social y para fijar la trayectoria de la agenda de «problemas» que requerían intervención estatal.

$\mathrm{Su}$ trayectoria profesional estuvo desde un principio marcada por el objetivo de fomentar el establecimiento de lazos entre el campo médico local y el europeo, en especial el francés, que era el que se mostraba más consolidado y dinámico. Durante la década de 1870 como director de la Revista Médico Quirúrgica, además de potenciar objetivos médico sociales por su relación con lo urbano, ensalzó fuertemente la importancia del establecimiento de tales vínculos. Con ello se cumplían distintos objetivos relacionados con la promoción del conocimiento médico y con la obtención de legitimidad por los médicos jóvenes interesados en la función pública. Fue en tal sentido significativo el incremento de los canjes con revistas europeas y el renovado interés por los reglamentos, ponencias y conclusiones de los congresos médicos internacionales ${ }^{34}$. El gran mérito de la revista y de su grupo impulsor fue por lo tanto su disciplinado intento de adherirse a las corrientes médicas internacionales que, con raíz en Europa, fluían con ímpetu para esas fechas. Este hecho no fue sin duda sólo el producto de una peculiar coyuntura local, sino que obedeció en buena parte al creciente impulso de grupos e instituciones médicas de algunos países centrales por difundir su imagen exterior, proceso que cobraría mucha mayor intensidad hacia fines de siglo, cuando se entremezcló de una manera importante con lo que algunos autores han denominado la «nebulosa reformadora» ${ }^{35}$.

${ }^{33}$ Adriana Álvarez señala que Coni, a lo largo de su carrera, obtuvo doce diplomas de instituciones y asociaciones nacionales y 46 de academias europeas y americanas. Álvarez y Carbonetti, 2008: 51. Coni, 1918a.

${ }^{34}$ González Leandri, 1999.

35 Prochasson, 1988. Topalov, 1999. 
Sus primeras inquietudes se orientaron hacia la demografía y la estadística. En 1879 viajó a Europa enviado por la oficina de estadística de la provincia de Buenos Aires, con el objetivo de establecer vínculos con oficinas análogas. Alrededor de esa fecha se fueron afianzando sus redes de contactos con académicos, higienistas y reformadores, que ya había comenzado a explorar años antes desde la Revista Médico Quirúrgica, cuestión a la que dedicaría en el futuro un importante esfuerzo. Fruto de esos contactos previos y de su estancia, que le permitió observar en el terreno los resultados de las políticas sanitarias e higiénicas europeas, fue la elaboración por parte de Coni, en solitario y en colaboración, de una serie de proyectos a ser aplicados en Buenos Aires. Bien mirada, dicha serie puede ser vista como el indicio de una «agenda de cuestiones problemáticas» cuya atención debía priorizarse según lo indicaba la experiencia europea por un lado y las condiciones locales por otro. Estas últimas estaban definidas por la índole misma de los problemas a ser atajados y las formas de hacerlo (urbanismo descontrolado, enfermedades infectocontagiosas, moralidad, etc.), y por las limitaciones institucionales, profesionales y técnicas propias del país ${ }^{36}$.

El más importante de ellos fue el de creación de la Asistencia Pública, cuya primera propuesta por parte de Coni fue del año 1878. El proyecto emulaba casi literalmente el modelo de la Asistencia Pública creado por Thiers en París. Sin embargo, junto al propio Coni, Mallo y otros médicos, propiciaron un intenso debate en el que se sopesaron con bastante cuidado las posibilidades de aplicación de modelos de ese tipo al medio local ${ }^{37}$. Una segunda propuesta fue la reglamentación de la prostitución, que fue aplicada por la Municipalidad de Buenos Aires sólo de manera parcial. Para ello llevó a cabo Coni un estudio de la legislación y el funcionamiento de dispensarios sanitarios de París, Bruselas, Roma y Turín que incluyó visitas a algunos de ellos ${ }^{38}$. Un tercer proyecto pretendía el establecimiento de una inspección médica de las escuelas de San Telmo y Catedral al Sur, que no prosperó en lo inmediato. Lo más destacado fue que para las dos últimas iniciativas tomó como modelo el servicio sanitario de Bruselas (Bureau d'Hygiene de Bruxelles). Durante su estancia europea, Coni estableció un sólido vínculo con su director, Eugenio Janssens, cuyas opiniones y trabajos citaría en múltiples ocasiones con bastante profusión ${ }^{39}$. Desde entonces en gran parte de sus propuestas, sobre todo aquellas institucionalmente más relevantes, como la reforma de la Asistencia

\footnotetext{
${ }^{36}$ Coni, 1918a: 224-244 y 300-353.

37 Coni, XVI/4 (23 de mayo, 1879). Crider, 1976: 91-120.

${ }^{38}$ Coni, 1918a: 183-217.

${ }^{39}$ Coni, 1887: 23. Coni, 1918a: 224-244.
} 
Pública en los 90, el modelo de sanidad belga figuraría como importante referente organizativo.

Un segundo viaje lo realizó en 1884 comisionado por la provincia de Buenos Aires para presentar el Censo General de la provincia de 1881 y el Anuario Estadístico de 1882 (en francés) en el Congreso Internacional de Higiene. Aprovechó su estancia en Europa para estudiar también cuestiones de higiene y visitar establecimientos sanitarios. A su retorno, fundó y organizó la Ofícina estadística Municipal de Buenos Aires en 1887, y en 1891 la Oficina Demográfica del Departamento Nacional de Higiene. Preparó además un volumen en francés, Progrès de l'hygiéne dans la Repùblique Argentine, destinado a ser presentado en el congreso internacional de Viena de 1887. Se inspiró en la compilación L'étude et le progrés de l'hygiene en France de 1878 á 1882, presentado por la sociedad de Medicina pública de París en el Congreso de Higiene de Ginebra de 1882, de los doctores Napias y Martin y especialmente en su prefacio, a cargo del doctor Brouardel, quien incitaba a la realización de trabajos similares en otros países en futuros congresos, para, según sus palabras «tener una idea de conjunto de las tendencias actuales de la higiene» ${ }^{40}$.

Este libro es el que mejor muestra el papel de Coni como hombre puente entre distintas esferas, dentro de la administración local y en ámbitos más globales, como el delimitado por los congresos internacionales de Higiene y Demografía de la época. A tono con el pensamiento higienista predominante, los problemas sociales y colectivos de la población fueron aquí considerados por Coni como eminentemente urbanos y reducidos a problemas sanitarios, de saneamiento y construcción de servicios colectivos. Sin embargo fue en el tratamiento que dio a los problemas de la higiene infantil, en sus fases asistencial y educativa (con la escuela como «agente de moralidad»), donde afloró de una manera más intensa una mirada que hizo de lo social algo más sofisticado y matizado, a través de su vínculo con la idea de prevención como cuestión estratégica. Se trató a su vez del capítulo en el que más se vieron enfatizadas las influencias y comparaciones (con las «comissions de batiments scolaires» de Francia, Suiza y Bélgica) y en el que su compromiso se notó más decidido ${ }^{41}$.

Como su nombre, heredado de la iniciativa francesa previa, en parte lo indica, se trató también de una obra con una fuerte carga propagandística y de difusión, muy notoria en algunos pasajes donde se ensalza la tarea realizada por la Municipalidad de Buenos Aires, institución impulsora del proyecto ${ }^{42}$. Sin

${ }^{40}$ Coni, 1887: VII-VIII; 1918a: 224-227.

${ }^{41}$ Coni, 1887: 17-28. 1918a: 162-182.

${ }^{42}$ Complementaba un importante esfuerzo de difusión del gobierno argentino, que organizó una exposición especial en el congreso de Viena. Se presentaron todo tipo de publicaciones, 
embargo no deja de mencionar aquí y allá ostensibles retrasos, pero también diferencias propias de lo que describía como un país joven, aunque tampoco omite citas donde algunos comentaristas señalaban las favorables condiciones argentinas respecto a los servicios franceses ${ }^{43}$. Sin embargo, dadas las formas del progreso, a veces mejores condiciones implican también atraso.

Menciona los proyectos municipales de Buenos Aires en relación con el saneamiento, asfaltado, obras y servicios públicos, asilos y hospitales, y casas para obreros y, de manera especial, la existencia de un instituto bacteriológico Pasteur en la Universidad, un laboratorio microbiológico, un servicio de desinfección y una oficina estadística en la Municipalidad ${ }^{44}$. Dedica un apartado especial a la descripción de la «Ciudad Higiénica de La Plata» ${ }^{45}$. Con minuciosidad se describen organismos y servicios locales y se transcriben extensos informes, proyectos, legislación y reglamentos ${ }^{46}$. En ese sentido se trata de una obra colectiva en la que Coni actuó como vector y traductor. Pero al mismo tiempo es una obra muy personal, por la agenda misma de los problemas que realza, y sobre todo por la utilización de un tono que muestra la clara vinculación a, y entre, dos mundos: propagandista orgulloso de lo argentino y al mismo tiempo difusor pertinaz de iniciativas y modos institucionales franceses y belgas.

\section{Internacionalidades renovadas. Higiene y moderna cuestión social}

\section{A) Crisis y nuevas ansiedades}

La crisis del 90, de raíz local pero con marcadas connotaciones y consecuencias internacionales — una muestra más de la fuerte interdependencia

como los cinco volúmenes de observaciones atmosféricas realizadas por Observatorio de Córdoba y una serie de boletines estadísticos.

${ }^{43}$ Señalaba por ejemplo que «los hábitos y condiciones de vida de nuestras clases proletarias ofrecen grandes diferencias con respecto a las naciones europeas». Coni, 1887, 7. Citaba también al doctor Mangenot, médico inspector de las escuelas de París, quien en un trabajo sobre la inspección higiénica en diferentes países, al referirse a la República Argentina expresaba: «Il faut reconnaire que sur ce terain de a medication préventive, cette petite république est plus avancée que la notre», Revue d'higiene et de police sanitaire, VIII/11 (20 de noviembre de 1886): 939, citado por Coni, 1887: 28.

${ }^{44}$ Coni, 1887; 83-86, 160-165, 201-206, 258. Con respecto a las ideas sobre saneamiento urbano, hace referencia a los trabajos señeros de J. B. Fonssagrives, Higiene et assainissement des villes, París, 1874.

${ }^{45}$ Coni, 1887: 160-161.

${ }^{46}$ Ver en especial el capítulo VIII, Organization Sanitaire, Coni, 1887: 160-161 y 247-266. 
mundial en términos comerciales y económicos de la época- puso en entredicho las ideas de progreso indefinido sostenidas con vigor por políticos, funcionarios y académicos durante la década anterior y que había hecho carne en sectores cada vez más amplios de la sociedad. Sus consecuencias políticas y económicas hicieron que se tomara mayor conciencia de la existencia de problemas sociales, como los de la vivienda, la sanidad y salud pública, el aumento de la criminalidad urbana y la protesta obrera, consecuencia en gran medida de la inmigración masiva, la urbanización y la industrialización, que estaba afectando al país y de la necesidad de aplicar correcciones que pasaban en muchos casos por la reformulación de la política pública. Emergía de tal forma una nueva y moderna «cuestión social» que fue interpretada por una parte de las elites gobernantes como un desafío más amplio a los fundamentos del orden político, económico y social de comienzos de siglo. Se trató en gran parte de un proceso de conflicto social y transformaciones intelectuales que paulatinamente se fue acelerando hacia comienzos del siglo $\mathrm{XX}^{47}$.

A ello se sumó el hecho de que, en forma un tanto paradójica, el reordenamiento político que se produjo tras la fracasada revolución del 90, fruto en parte de la debilidad de los elencos gobernantes, permitió el afianzamiento de determinadas elites técnicas, como los urbanistas y los médicos, que vieron así aumentada su influencia y su autonomía en los procesos de definición de «problemas» sociales y públicos y en el diseño de la intervención estatal para paliarlos ${ }^{48}$.

Con respecto al área de Higiene y Asistencia, hacia 1895, con motivo de la renovación de la confianza depositada por el gobierno en José María Ramos Mejía como director del Departamento Nacional de Higiene, distintos sectores de la opinión y de la prensa señalaban que la corporación médica había alcanzado un importante nivel de éxito institucional que le permitía fijar la agenda de muchos de los problemas sociales vigentes, y vaticinaban un futuro todavía más halagüeño. Un importante factor fue el papel relevante que comenzó a jugar el Consejo Nacional de Higiene, una vez que se precisaron por ley algunos de los rasgos de su efectivo alcance nacional. Los intentos de su director de consolidar lo que llamaba el «rol complejo» de la institución, que implicaba un mayor equilibrio entre las medidas higiénicas y de control sanitario «externo» e «interno», pretendía erigirse, por un lado, en árbitro de cuestiones sanitarias, y por otro en un baluarte en cuanto a la definición de

47 Zimmermann, 1995. Botana y Gallo, 1997. Suriano, 2000. Lobato, 2000. González Leandri, González Bernaldo de Quirós y Suriano, 2010: 153-206, ver en especial el capítulo 4: «La crisis de 1890, los trabajadores y la emergencia de la cuestión obrera».

48 González Leandri, 2010; 2012: 125-158. Gorelik, 1998. 
ámbitos de actuación de los poderes públicos, en temas que conformaban la moderna cuestión social ${ }^{49}$. Se trató de un tema de política local, pero que, por la raíz de los problemas que pretendía atajar, anclados muchos de ellos en los desbordes de una inmigración masiva y en la difusión de enfermedades extendidas globalmente, tenía un fuerte cariz internacional.

Se llegó a esa nueva instancia por medio de debates en el seno del gobierno y de la corporación médica. Se sopesaron con minuciosidad las distintas alternativas que ofrecían corrientes de pensamiento y actuación sanitaria y social vigentes en los distintos países europeos - la ley inglesa de protección de la salud de 1875, la experiencia alemana y la «sagacidad de la legislación italiana»- y en Estados Unidos. Una figura clave en ese sentido fue Guillermo Udaondo, quien en informes al ministro del Interior y en artículos académicos se ocupó de delimitar para el ámbito local una higiene pública o administrativa que permitiera incrementar la eficacia de la intervención higiénica gubernamental ${ }^{50}$.

La índole internacional de la trama de problemas que se vieron obligados a enfrentar algunos de los actores relevantes de ese proceso hizo sin embargo que comenzaran a asumir posiciones que abrían el camino hacia la adopción de actitudes más tamizadas con respecto a la relación con el entorno internacional. En determinados ámbitos, especialmente en aquellos que más tenían que ver con la aplicación de políticas sanitarias, los modelos foráneos, sobre todo los europeos, fueron analizados dentro de un marco de recepción connotado por la intención de la dirección del Departamento de Higiene de «nacionalizarlo», lo que significaba distintas cuestiones a la vez. En primer lugar, la intención de que llegara a todo el territorio del país y generara gestos de alto contenido simbólico. Esto implicaba, en forma paralela, el mantenimiento de una relación más fluida con los países vecinos, de cuyo cónclave había surgido el mandato de crear un Departamentos de Higiene de alcance nacional ${ }^{51}$. Por otra parte, en lo relativo a la aplicación de políticas, reglamentos y controles, también hacía referencia a la necesidad de atender con más esmero a la especificidad local. Ramos Mejía consideraba que en muchos sentidos ello podía entrar en colisión con los modelos institucionales europeos, sobre todo la centralidad técnica francesa, que se pretendía asimilar.

49 González Leandri, 2010: 59-85.

${ }^{50}$ Udaondo, 1892: 18-27. Años más tarde, desde una perspectiva más fuertemente «bacteriologizada», Emilio Coni señalaría las limitaciones de algunas de esas iniciativas. Las atribuía al hecho de que «las doctrinas de Pettenkofer prevalecieron por desgracia en el seno del Departamento de Higiene». Coni, 1896: 192.

51 Veronelli, 1975: 43-45. González Leandri, 2010: 59-85. Ramos Mejía, 1898: 14-23. 
Una mayor atención a las limitaciones políticas e institucionales del país y especialmente a su carácter de gran receptor de inmigración implicaba, según su criterio, un mayor acercamiento a las iniciativas de legislación y control sanitario adoptados por Estados Unidos ${ }^{52}$.

La memoria del Departamento, que abarcó los años transcurridos entre 1895 y 1898 , se muestra bastante escéptica con respecto a la política sanitaria internacional europea, a la que se consideraba guiada sobre todo por intereses comerciales, juicio que se hacía extensivo también a las conferencias de Higiene internacionales ${ }^{53}$.

Sin embargo, en otros planos estas opiniones, vertidas desde lugares institucionales importantes, no interfirieron en la fluidez de contactos e intercambios que con el tiempo se intensificaban notoriamente. Emilio Coni, por ejemplo, ya era un médico internacionalmente reconocido e incrementó su participación en congresos e iniciativas de carácter internacional. Con sus nombramientos como miembro honorario de la Sociedad Francesa de Higiene Pública de París (1893) y de la Academia de Medicina de París (1897), cosechaba los frutos de su insistencia en convertir la internacionalidad en uno de los rasgos característicos de los higienistas argentinos. Pero sus posteriores comentarios ambivalentes e incluso negativos sobre la realización de congresos panamericanos muestran que, según su criterio, esta no debía ser indiscriminada, sino más bien orientada en una dirección bastante específica ${ }^{54}$. Curiosamente, sin anclaje académico e interrumpido de forma abrupta su paso por el funcionariado municipal, su figura se fue opacando en el ámbito de la política pública local. Tomó en consecuencia la decisión extrema de radicarse, al menos de forma temporaria, en Francia. Cumplía así, en circunstancias bastante distintas, un tercer periplo de dos años de duración que da pie para la observación de otro de los modos de la circulación - de ideas, innovaciones, prácticas institucionales y eventos - que tuvo que ver, tal vez a pesar del propio Coni, más que con la comunicación entre expertos con la conformación de una opinión pública y de un imaginario social de la modernidad en el que la higiene se abría paso de una manera importante.

52 Ramos Mejía, 1898: 490.

${ }^{53}$ Con respecto a estas últimas, opinaba su director: «En estas conferencias no priman como pudiera creerse los intereses sanitarios; cada uno de sus miembros tiene ante sus ojos las instrucciones reservadas de sus gobiernos y detrás de sí el ministro diplomático que dirige sus pasos entre el complicado laberinto de la política europea que sacrifica sin piedad todo aquello que se le oponga» Ibidem: 18-25, 448-458.

${ }^{54}$ Coni, 1918: 263-273, 461-591. Álvarez, 2008: 88. Veronelli y Veronelli Correch, 2004: Tomo 2, 277-334. 
Para sufragar su estancia en París, Coni llegó a un acuerdo con el periódico La Prensa, el de mayor tirada en la Argentina del momento, para realizar informes sobre condiciones higiénicas y saneamiento urbano. Dichos informes, condicionados en parte por el arreglo previo entre las partes, fueron publicados con una periodicidad mensual como cartas al director enviadas «desde París» ${ }^{55}$.

A través de un discurso envolvente y mezclado, muy propio de los higienistas de la época, las cartas de Coni combinaban descripción de artefactos, instituciones $\mathrm{y}$ asociaciones, sugerencias y consejos. El señalamiento de emulaciones posibles dejaba entrever al mismo tiempo la tensión provocada por el permanente afán comparativo. Desfilaban alrededor de las veintiún cartas incubadoras para bebés, estufas de desinfección, libros para la instrucción de las madres, información sobre las «maternidades artificiales», asociaciones filantrópicas y protectoras de ciegos y sordomudos, los avatares, polémicas y competencias del suero antidiftérico, reglamentos y ordenanzas de todo tipo, en especial vinculadas al saneamiento urbano y ambiental. Resalta la descripción de congresos internacionales y exposiciones, sobre todo el de Budapest, por las presentaciones de Löffer (Greifswald) y Roux (París) sobre el suero antidiftérico, la exposición internacional y colonial de Lyon, el «consenso» alcanzado entre partidarios de Koch y Pettenkofer en el congreso de higienistas alemanes, y los congresos internacionales de protección de la Infancia en Florencia y de Higiene y Demografía de Madrid ${ }^{56}$. También relata el paso por Europa de médicos argentinos ${ }^{57}$. La serie por tanto obtenía su fuerza narrativa del hecho mismo de esa combinación en apariencia azarosa que daba un halo cosmopolita y moderno a la vez. Además se incluían cuestiones que vinculaban el conocimiento experto con cuestiones relevantes de la cultura de fin de siglo y los nuevos modos de la vida urbana, como la promoción de la «higiene popular» o las discusiones en el seno de la academia francesa sobre la utilidad y los posibles perjuicios del uso de la bicicleta ${ }^{58}$.

La serie combinaba crónicas actualizadas de las novedades, conferencias y debates en el seno de las corporaciones e instituciones médicas y sanitarias, sobre todo de Francia (Academia de Medicina, Instituto Pasteur, Asistencia Pública), pero también de Alemania, Bélgica, Inglaterra e Italia. En varias cartas se menciona la utilidad de establecer en Argentina escuelas de ingenieros sanitarios y plomeros al estilo inglés; de Italia extrae Coni la idea de

${ }^{55}$ Coni, 1918a: 383-393. Veronelli y Veronelli Correch, 2004: 306-308. Las cartas fueron reunidas y publicadas en forma de libro un año después. Coni, 1896.

${ }^{56}$ Coni, 1896: 10-19, 122-124, 156-157, 220-222; 1918a: 387-393.

${ }^{57}$ Destaca el paso del doctor Malbrán, que venía de realizar estudios conjuntos con el doctor Aronson en Berlín sobre los sueros antidiftéricos de Roux, Behring y Aronson. Coni, 1896: 17-175.

58 Coni, 1896: 158-166, 177, 188. 
crear en Buenos Aires una escuela de Higienistas, como la dirigida por el Dr. Pagliani, que, según su criterio, permitiría paliar en Buenos Aires la falta de auténticos especialistas en higiene ${ }^{59}$.

Al igual que en su anterior libro Progrés de l'higiene dans la République Argentine, los problemas sociales colectivos son descriptos como de raíz eminentemente técnica, con matices morales, solucionables por una combinación de saneamiento urbano y filantropía. Sin embargo aparecen algunos indicios de que la cuestión se tornaba más compleja. Uno de ellos fue la reseña, importante aunque colateral, del libro de Lombroso Gli Anarchi ${ }^{60}$.

Sin embargo, para ese entonces las ideas higienistas clásicas como las de Coni comenzaban a convivir dentro de las estructuras institucionales con otras que, sin salirse de los marcos ideológicos en boga, comenzaban a plantear nuevos diagnósticos y nuevas actuaciones. Desde el Departamento Nacional de Higiene se iniciaron nuevas acciones que mostraban una interesante reorientación en ese sentido. Si bien en los 80 la Asistencia Pública a cargo de Ramos Mejía había intentado paliar problemas de pobreza, que eran definidos más bien como de raíz individual, a partir del argumento filantrópico de ayudar con «orden», en los 90 el Departamento Nacional de Higiene se guiaba por ideas renovadas acerca del pauperismo, que colocaban mayor énfasis en los aspectos socio laborales ${ }^{61}$. De tal forma, entre las varias iniciativas adoptadas tendientes a la «defensa sanitaria del medio interno», se creó la inspección de fábricas e higiene industrial a cargo del doctor Aberastury. Orientado por la experiencia inglesa en la materia realizó varios informes que derivaron, en un intento de reglamentación, una de las primeras incursiones estatales en ese aspecto específico ${ }^{62}$.

Ramos y Aberastury consideraban que la regulación de la Higiene Industrial era clave y consistía sobre todo en paliar un entramado de peligros derivados de la creciente internacionalización de la economía, a la que se sumaba la protección de ciertas industrias por parte de los gobiernos por motivos fiscales y económicos. Consideraban que dadas las pésimas condiciones en que los trabajadores, muchas veces mujeres y niños, realizaban sus tareas, no era de extrañar que «cada día fuera más poderosa la lucha entre el obrero y el capital» ${ }^{63}$. Pensaban sin embargo que la solución era relativamente sencilla en la medida que el Estado se involucrara de lleno y dictara normas

59 Ibidem: 124-128, 194-196, 201-204.

${ }^{60}$ Ibidem: 20-24.

${ }^{61}$ Ramos, 1898: 14-18. González Leandri, 2008: 130-132.

${ }^{62}$ Ramos, 1898: 14-18. Aberastury, IV/46-47 (diciembre de 1894): 1257-1278. Recalde, 1997: 97-162.

${ }_{63}$ Ramos, 1898: 531. 
legales que regularan la duración de la jornada de trabajo y la salubridad de los locales industriales afectados y todos los demás aspectos de la producción industrial que pudieran incidir sobre la salud de la población en su conjunto. Sus intenciones se vieron rápidamente frustradas por la falta de atribuciones, que los obligó a contar con la buena voluntad de los industriales, la que cesó tras conocerse los primeros informes ${ }^{64}$.

\section{B) Higiene social y funcionarios reformistas}

Las ideas que dentro del marco del conservadurismo liberal esbozaba Ramos Mejía desde el departamento Nacional de Higiene cambiarían parte de su sentido hacia comienzos de siglo. La clave radicó en que la propia dinámica de la cuestión social hizo que el debate se ampliara a la propia capacidad de las instituciones liberales clásicas para proveer soluciones a los nuevos problemas.

Esta deriva tuvo un curioso itinerario en el caso de las instituciones higiénicas que fueron representativas del universo de ideas, propuestas institucionales y de problemas más amplios relacionados con el auge de la ola reformista de la década de 1910. Una vez que se hubiera retirado Ramos Mejía de la dirección del Departamento, el experimento roquista de volver al anterior sistema de colocar a su frente a políticos notables, aunque se tratara de higienistas como Eduardo Wilde, comenzó a sonar un tanto anacrónico y se saldó con un fracaso. Para salvar la situación se recurrió en 1902 a Carlos Malbrán, una figura que, sin ser ajena a las redes políticas gobernantes, estaba legitimada por su carácter de bacteriólogo que presentaba como credenciales su alta internacionalidad, con estancias y visitas en centros europeos, y la realización de experimentos conjuntos con investigadores alemanes. El nuevo tono de los tiempos, en el que un tipo específico de internacionalidad científico-técnica, en general vinculada a la experimentación bacteriológica, cobró mayor peso, hizo que con Malbrán se viera reforzada en el Departamento de Higiene una línea técnica y de investigación que promovería una creciente intervención en las provincias a través de campañas contra enfermedades locales (paludismo, lepra $)^{65}$. Esta pugnaría por realzar de una manera más precisa que en décadas anteriores, y con éxito desigual, su papel como definidora de la agenda de problemas higiénicos y sociales públicos. Su carencia para el logro de tales objetivos era la falta de una ley que apuntalara sus ansias de «centralidad

\footnotetext{
${ }^{64}$ Ibidem: 500-535.

${ }_{65}$ Araoz Alfaro, La semana médica, Tomo Cincuentenario/primer fascículo: 519-530. Malbrán, 1931.
} 
técnica», en detrimento, sobre todo, de los Consejos de Higiene provinciales. De la misma manera que sucedería un poco más adelante con el proyecto de ley del trabajo, regular esta cuestión formó parte importante de la agenda de los liberales reformistas liderados por el ministro del Interior Joaquín V. González. Este apadrinó la idea de promulgar una ley de sanidad nacional que permitiera lograr aquellos objetivos por los que los médicos apegados a la función pública habían batallado durante décadas. Se elaboró con ese fin un proyecto basado en información detallada recabada de los modelos, francés, alemán, inglés y belga, y en el que intervinieron médicos relevantes como el propio Malbrán y José Penna, quien lo sucedería años más tarde al frente del departamento ${ }^{66}$. El destino sufrido por la propuesta, que fue finalmente rechazada, muestra cómo cuestiones claves del sistema político local, como el régimen federal de gobierno, imponían condiciones a la circulación, recepción y adaptación de modelos institucionales que se había logrado instalar en ciertos organismos técnicos y asistenciales de la capital federal.

Esa faceta del Departamento de Higiene eminentemente técnica vinculada al control sanitario a partir de un despliegue bacteriológico, se vio complementada por otra más «social», con la que mantenía un vínculo fluido. La mayor influencia que esta última comenzó a adquirir indicaba cambios en el sentido de la relación entre expertos y agencias estatales como resultado de varias cuestiones entrelazadas ${ }^{67}$.

Una de ellas fue el aceleramiento del ritmo de los intercambios vinculados a la «nebulosa reformista» internacional. Un indicio importante de ese proceso fue el papel significativo que en la exposición universal de París de 1900 adquirió el pabellón dedicado a la «economía social». Si bien el mensaje que quería transmitir la exposición era de plena confianza en los logros del capitalismo industrial y el auge del comercio, no podía ocultarse la ansiedad que para la «paz social» producían los crecientes conflictos entre los trabajadores y el capital, fenómeno bastante globalizado que afectaba a todas las grandes urbes del mundo. Bajo el paraguas de la «economía social», concepción impulsada por el teórico francés Charles Gide, el pabellón incluía todo tipo de iniciativas de reformas que iban desde las más «estatistas», de origen alemán, hasta las más asociativas y cooperativas, como las francesas y belgas ${ }^{68}$. En

${ }^{66}$ Araoz Alfaro, La semana médica, Tomo Cincuentenario/primer fascículo: 519-530.

${ }^{67}$ González Leandri, 2012: 125-158.

${ }^{68} \mathrm{Si}$ bien la economía política era para Charles Gide la ciencia de la argumentación de la riqueza, la economía social incluía todo tipo de esfuerzos por atemperar, socializar y mutualizar los dolores de la transformación capitalista. Era la ciencia de la «paz social». Rodgers, 1998: 12-16. 
general se proponían reformas de tipo gradual que implicaban un cambio en las políticas públicas que paliara los aspectos más negativos del laissez faire sin caer por ello en el socialismo de Estado. Efectivamente, todo un arsenal de propuestas de reforma que iban desde planes para la construcción de casas para obreros, movimientos de temperanza y lucha contra el alcoholismo y la prostitución, movimientos cooperativistas de todo tipo, seguros sociales para trabajadores, planes de reforma de las jornadas de trabajo y una concepción del higienismo abierta a los problemas laborales y a los accidentes de trabajo, se hallaban a disposición de movimientos sociales, intelectuales y gobiernos de todo el mundo, como los argentinos, abiertos a la experimentación reformista. Emergía también un vocabulario que hacía de lo social, basado en las pretensiones de interpretación científica de la realidad promovida por las nuevas ciencias sociales, su eje central. Así circulaban a nivel global los términos «social problem», «économie sociale» y «Sozialpolitik», y otros más específicos pero con repercusión entre determinados movimientos sociales y agrupaciones de trabajadores como «solidaridad», «mutualismo» y «cooperativismo», entre otros ${ }^{69}$.

Para esos años los Anales del Departamento de Higiene, y también la prensa periódica, dieron minuciosa cuenta de ese proceso de circulación internacional y tomaron nota de la gran cantidad de congresos y exposiciones internacionales, relacionados con cuestiones higiénicas y temas sociales (vivienda obrera, prostitución, alcoholismo, legislación laboral), que tuvieron lugar durante esos años, así como del crecimiento exponencial de la participación de médicos, profesionales y funcionarios argentinos en tales eventos.

Vinculada de manera estrecha pero compleja a esa primera cuestión, otra de las causas de esas variaciones entre expertos «sociales» y el Estado estuvo relacionada con la reconfiguración del campo académico que tuvo lugar en la década de 1890, muy evidente en el caso de la profesión médica. Al apuntalar mecanismos reglados de reproducción del cuerpo profesional local, la experimentación y el valor simbólico de la práctica académica, esa reconfiguración permitió la conversión de sus prácticas y conocimiento en «saberes de estado ${ }^{70}$. A tono con esas heterogéneas corrientes de ideas reformistas que circulaban a nivel internacional y con las transformaciones sociales e intelectuales internas, fue importante para la trayectoria local de la Cuestión Social, entendida como preocupación pública, la creación de polos académicos como la Universidad de la Plata y la Facultad de Filosofía y Letras de la Universidad de Buenos Aires, que se adhirieron a esa tendencia. Con ellas

69 Ibidem: 29.

70 Terán, 2000. Zimmermann, 1995. González Leandri, 2012: 125-158. 
las nuevas ciencias sociales adquirieron un lugar relevante en la producción de un nuevo «sentido social» y para orientar las posibles reformas. En 1904 se creó la primera cátedra de Sociología y su titular, Ernesto Quesada, buscó sus fuentes en los economistas de la escuela histórica alemana y en la «economía social» de Charles Gide que, como hemos visto, implicaba un moderado programa de reformas que incluía una participación más activa del Estado ${ }^{71}$.

Se conformó así un campo intelectual muy fluido y de notable circulación interna y múltiple que cuajaría años más tarde en instituciones polifacéticas como el Museo Social Argentino, que entablaría una relación cercana con ciertas agencias estatales y el Parlamento ${ }^{72}$. Determinados médicos fueron un elemento central de ese campo, sobre todo los socialistas (aunque no sólo ellos), que contaban con figuras de peso como Juan B. Justo y Nicolás Repetto, reconocidos por su internacionalidad, que no era atribuible en exclusiva a su pertenencia a un movimiento, el socialista, que hacia de ella uno de sus pilares ${ }^{73}$. Otro médico, también socialista, de notable circulación y actividades transversales en distintas instituciones y centros académicos, como la Facultad de Filosofía y Letras, fue Augusto Bunge.

Como consecuencia de ello un lenguaje de lo social, así como el adjetivo «social», comenzaron a teñir los ámbitos más variados y se hizo carne en la propia actividad médica y, como no podía ser de otra manera, en la propia higiene. Tal es así que personajes tan connotados como Eduardo Wilde, al comentar su participación en 1904 en el congreso internacional de Higiene y Demografía de Bruselas, comentaba su importancia sociológica ${ }^{74}$. El propio Coni, quien giró con los años hacia un higienismo más asistencialista, comenzó a definirse a sí mismo también como médico sociólogo ${ }^{75}$. La Semana Médica abrió una sección de Higiene Social, que incluía noticias sobre higiene infantil, salud maternal, vivienda obrera, alcoholismo y prostitución.

El tono de la época con respecto a la cuestión social, y las influencias que se manejaban, quedó claro en la propuesta de Emilio Coni de establecer una «Alianza de Higiene Social» que movilizara a organismos estatales y otras instituciones y asociaciones para combatir «los grandes enemigos de la humanidad, la tuberculosis, el alcoholismo, la avarisosis, la habitación insalubre y

71 Zimmermann, 1995: 83-100. Buchbinder, 2012: 161-213.

${ }^{72}$ Becerra, 2009: 209-238.

${ }^{73}$ Repetto, 1955: 59-191. Ver sobre todo los capítulos «Italia», «Francia», «Suiza»y «Alemania».

${ }^{74}$ Wilde señalaba: «Este congreso ha reunido en Bruselas a la mayor parte de los hombres de ciencia europeos y americanos que se ocupan de las cuestiones de higiene y demografía, tan ligadas a las más interesantes de legislación y sociología». Wilde, XI/1 (enero de 1904): 16-17.

75 Coni, 1918 b. 
la mortalidad infantil», y promover el mutualismo ${ }^{76}$. Debido a su trayectoria se mostraba influido por la política social francesa, sus antecedentes republicanos y la impronta de León Bourgeois, filósofo del solidarismo, impulsor de la Alliance d'Hygiéne Sociale y presidente honorario del Musée Social ${ }^{77}$. Pensaba que dichas iniciativas eran trasladables no sólo al medio argentino sino también al resto de Latinoamérica. Teniendo en cuenta su decepción con las elites políticas locales, su defensa del mutualismo - en el que coincidía con los socialistas, quienes también desconfiaban de la «política criolla»— puede ser vista como un vericueto más de la compleja relación entre circulación internacional de ideas y modelos y su recepción local. Se diferenciaba en ese aspecto de otros médicos notables, más arraigados en el establishment, como José Penna, que miraba con mejores ojos una intervención estatal más fuerte «a lo Bismark».

Tales propuestas fueron hechas en el marco del II Congreso Médico Latinoamericano que tuvo lugar en Buenos Aires en 1904 y reiteradas en otros como el de Montevideo de 1907. Esto nos conduce a otra de las características del proceso de circulación de ideas higiénicas y sociales de comienzos de siglo: el acelerado acercamiento entre las comunidades académicas médicas de América Latina. Como la propia iniciativa de Coni lo demuestra, los congresos y exposiciones médicas que tuvieron lugar en esas fechas se constituyeron en espacios dinámicos para la triangulación tanto de ideas y prácticas como de modelos institucionales. A ello hay que sumar su superposición con otros de índole panamericano que comenzaron a celebrarse en 1992, claro indicio del incremento de la relación académica con Estados Unidos ${ }^{78}$. Sin embargo esos contactos también recogían nuevos perfiles ideológicos que comenzaban a surgir en la región con posterioridad a la Guerra de Cuba. A partir de entonces, en parte gracias también a la iniciativa de Emilio Coni, en los Anales del Departamento de Higiene se incrementó de manera importante la publicación de informes de médicos latinoamericanos sobre la situación sanitaria de sus respectivos países ${ }^{79}$.

El clima de ideas reformista que cuajó en ámbitos académicos y militantes y que hizo de la Higiene Social uno de sus estandartes encontró un nicho

${ }^{76}$ Coni, 1918a: 480-593.

77 Donzelot, 1985.

78 Un listado de esos congresos puede consultarse en Álvarez, 2008. Amplias referencias al tema hace Coni en sus Memorias. Coni, 1918b: 183-227, 461-470, 480-593.

79 Así, por ejemplo, en 1903 y 1904, bajo el rubro «La Higiene Pública en América Latina», se publicaron informes sobre San Salvador, Venezuela, Costa Rica, y Bolivia, entre otros. Boletín del departamento nacional de Higiene, X/10 (octubre 1903): 472-477; X/11 (noviembre de 1903): 512-518; X/11 (enero de 1904): 29-31, 31-33. 
también en el espacio institucional. El impulso que le dio el Departamento de Higiene gozó del apoyo del Ministerio del Interior, que necesitaba insumos, de ideas y de información, para alcanzar el éxito en sus proyectos de regulación del mundo del trabajo y del conflicto social. Los informes que el departamento produjo, con cuyo objetivo tuvo que convertir de forma apresurada a médicos de sección en auténticos inspectores, fueron de notable importancia y sentaron las bases de una estructura técnico administrativa y de producción de ideas y estudios comparativos más especializada. En ese sentido destacó el informe elaborado por Augusto Bunge en 1904 sobre el trabajo industrial en Buenos Aires. Dicho informe, para el cual se inspeccionaron 1193 establecimientos, constataba, una vez más, que Higiene y Cuestión social formaban una amalgama que había que atacar en todos sus frentes: el específicamente laboral, vivienda, educación, prevención de plagas sociales como el alcoholismo y la prostitución ${ }^{80}$.

El informe concluyó que era imprescindible una legislación adecuada y una acción estatal más decidida y coordinada. Con ese objetivo en mente desde distintas instancias gubernamentales (el Ministerio del Interior, el Departamento de Higiene) se organizó el viaje del propio Bunge a Francia, Alemania y Suiza con el fin de recabar información e investigar sobre las nuevas políticas sociales aplicadas en dichos países. A diferencia de los anteriores viajes de Coni, donde las instrucciones eran más difusas, en este caso se trató de un mandato del Estado con fines bien específicos, orientados a una aplicación de la investigación realizada con objetivos políticos y legislativos más detalladamente programados. Cambiaba en cierta medida el tono de la relación con la nebulosa reformista internacional promovida y deseada por los distintos actores participantes en la trama de la Cuestión Social local.

De tal forma Augusto Bunge, militante socialista, se convirtió en una figura fundamental en ese entramado administrativo y técnico que se forjó dentro de la estructura estatal en los años de comienzos de siglo en relación con la Higiene y su vínculo con la más amplia cuestión social.

A su regreso, publicó Bunge en 1909 una serie de informes dirigidos al Departamento de Higiene y al Ministerio del Interior bajo el título de Los avances de la Higiene social. Se trató de una obra de gran envergadura, fruto de una trayectoria de casi una década de informes y trabajos, muy representativa de las interconexiones entre intelectuales, profesionales y agencias estatales ${ }^{81}$.

Además del minucioso estudio comparativo de la legislación y las iniciativas de los países visitados, que le permitió elaborar una visión original y

\footnotetext{
${ }^{80}$ Bunge, 1904: 337-364, 388-410, 435-448.

81 Bunge, 1909b: 191-242, 243-271, 289-381, 431-472, 485-599.
} 
matizada de determinados problemas sociales, lo más importante fue el lugar desde el que orientó la narración, que no era otro que la propia estructura administrativa del Estado. Su carácter de militante socialista no le impidió hablar desde ese lugar. Esto explica un tanto mejor su gradualismo, su posibilismo y el sentido que creía que debía darse al «saneamiento de las multitudes, obra social por excelencia» ${ }^{82}$. La cuestión no podía quedar en manos de la buena voluntad de los empresarios. Por otra parte, las asociaciones gremiales habían logrado importantes correcciones, pero sus fines eran muchas veces estrictamente económicos e insuficientes. Se imponía por tanto la intervención del Estado que debía emprender el camino de la leyes de protección del obrero, y ejecutar una profilaxis basada en la heterogénea combinación de iniciativas que actuaban bajo el paraguas de la «Higiene social» ${ }^{83}$. No se trataba de una cuestión solo de lucha ideológica sino, sobre todo, de la construcción de un estado moderno que excedía tal cuestión y que, según su opinión, «ha llegado a penetrar hasta en los círculos más conservadores - me refiero a los países que como Inglaterra y Alemania marchan a la cabeza de la cultura - la idea de que al lado de las funciones de contralor policial y de administración están las funciones sociales del Estado» ${ }^{84}$.

De la comparación entre lo que consideraba el carácter «eminentemente práctico» de la legislación e iniciativas sociales inglesas, y la meticulosidad y amplitud de la alemana y otros casos, extrajo la conclusión de que si bien la promulgación de leyes sociales era fundamental, el destino de las políticas higiénicas y sociales se jugaba realmente en otro campo, en el de la consolidación de un sistema de inspección y contralor con amplias capacidades ${ }^{85}$. Si bien mostró muchas precauciones a la hora de incorporar legislación social europea a la Argentina, la envergadura del trabajo comparativo realizado y las interconexiones, institucionales, que se pusieron en juego para lograrlo, puede decirse que Augusto Bunge fue un eslabón más de la nebulosa internacional reformadora de comienzos de siglo, que aunaba Higiene y Cuestión social y que, en parte, excedía el propio proceso de construcción estatal local. Se destacó Bunge por tanto por su relación con una serie de propuestas legislativas que, si bien fracasaron en su mayoría, debido sobre todo al franco resquebrajamiento político del régimen político de notables que regía entonces, fueron

82 Bunge, 1909b: 196-198.

83 Consideraba que «el término algo impreciso de Higiene Social» incluía medidas de fomento económico y policía sanitaria y comprendía «muchos otros problemas de previsión, asistencia y de enseñanza». Bunge, 1909b.

${ }^{84}$ Ibidem: 198.

${ }^{85}$ Bunge, 1909a: 11, 45-46, 71. 
fundamentales para forjar una cultura del estado en la que, a pesar de todos los avatares futuros, la intervención social pasó a ser considerada como una cuestión deseable y pertinente, más allá de sus logros efectivos.

\section{CONCLUSIONES}

En este artículo hemos descrito tres momentos que muestran el vínculo histórico que entre el siglo XIX y principios del XX se dio por una parte entre Higiene y Cuestión Social y, por otra, entre actores relevantes de ese proceso y determinados ámbitos internacionales, en los que las ideas de prevención y «salud como problema social» se desarrollaban y difundían con fuerza. Hacia mediados de siglo se observa una relevante circulación de expertos, muchos de ellos inmigrantes, con notable experiencia circulatoria previa, que la volcaban al medio local y, como en el caso de Puigari o $\mathrm{Mu}$ rray, actuaban como importante puente con sus colectividades académicas de origen y con los higienistas que se movían alrededor de las conferencias internacionales. Una vez consolidado el Estado nacional se destacó en el plano de la circulación internacional la figura de ciertos médicos jóvenes, como Emilio Coni. Estos en su avidez por influir y hacerse un hueco en el espacio académico e institucional descubrieron tempranamente el valor de los vínculos con ámbitos europeos internacionalizados. A través de su proyección exterior cumplió Coni un importante papel de «bisagra»: propagandista de los progresos, higiénicos, académicos y sociales de un país «nuevo» como la Argentina y, difusor de ideas y modelos de política higiénica y asistencial, en especial los franceses y belgas, que ansiaban influir y trascender internacionalmente en un mundo crecientemente interconectado. En el comienzo del nuevo siglo, en pleno auge y ansiedades de la moderna cuestión social y la «nebulosa reformista», médicos funcionarios sociales al servicio de agencias estatales como Augusto Bunge, definieron un modelo de circulación más estrictamente relacionado con investigaciones específicas orientadas a aplicaciones prácticas y a la producción de legislación social. A tono con la noción internacionalmente consolidada de Higiene social difundieron la idea de la importancia del apuntalamiento de las «dimensiones sociales del estado».

En los tres momentos históricos analizados, a pesar de que la circulación internacional de ideas sobre higiene era intensa, y en muchos casos imprescindible, se hizo presente entre los actores locales involucrados una cierta forma de eclecticismo, que mostró las inevitables tensiones entre los ritmos y modos de dicha circulación y los de la política y la construcción institucional y profe- 
sional locales. Así lo señalaron Golfarini y Coni, pero quien más afinadamente teorizó sobre esta inevitable tensión fue Augusto Bunge. En sus informes sobre los progresos de la Higiene Social afirmaba: «cometeríamos un error lamentable si nos apresuráramos a aplicar las peculiaridades de nuestro joven organismo cosmopolita una copia demasiado fiel de lo hecho en ese o aquel país de Europa». Para a continuación replicarse: «Pero conviene tener presentes las analogías de las sociedades, resultantes de los paralelismos de todo desarrollo económico. En muchos casos, por tanto a pesar de las diferencias de latitud o de raza, la igualdad de condiciones exigirá igualdad de medios, por que el metro tiene el mismo largo, exactamente, en Buenos Aires y en Tombuctú» ${ }^{86}$.

\section{BIBLIOGRAFÍA}

Aberastury, Maximiliano, «Higiene industrial, proyecto de ley. Clasificación de las industrias insalubres y peligrosas», Anales del Departamento Nacional de Higiene, IV/ 46-47 (diciembre de 1894): 1257-1278.

Ackerknecht, Erwin, «Higyene in France. 1815-1848», Bulletin of the History of Medicine, 2/ 22 (1948): 117-155.

Aisemberg, Andre Robert, Contagion: disease, government, and the «social question» in nineteenth century France, Stanford, Stanford University Press, 1999.

Alcalde González, Rafael, «La introducción y el desarrollo del Higienismo en España. Precursores, continuadores y marco legal de un proyecto científico», Scripta Nova, revista electrónica de geografía y ciencias sociales, 50/15 (octubre de 1999): s/n.

Álvarez, Adriana, «Tras la vida de un higienista y filántropo: Emilio Coni», Adriana Álvarez y Adrián Carbonetti (eds.), Saberes y prácticas médicas en Argentina. Un recorrido por historias de vida, Eudem, Mar del Plata, 2008: 29-94.

Araoz Alfaro, Gregorio, «La higiene y la sanidad en nuestro país. Esbozo histórico», La semana Médica, Tomo Cincuentenario/primer fascículo, 1944: 519-530.

Armus Diego, «El descubrimiento de la enfermedad como problema social», Mirta Lobato, Nueva Historia Argentina. Tomo V: El progreso, la modernización y sus límites (1880-1916), Buenos Aires, Sudamericana, 2000: 507-561.

Baldwin, Peter, Contagion and the State in Europe 1830-1930, Cambridge, Cambridge University Press, 1999.

Becerra, Malena, «La economía social argentina en las exposiciones internacionales. La exhibición del Museo Social Argentino en la Exposición Universal e Industrial

${ }^{86}$ Bunge, 1909b, 201-202. 
de Gante (1913)», María Sivia Di Liscia y Andrea Lluch (eds.), Argentina en exposición. Ferias y exhibiciones durante los siglos XIX y XX, Sevilla, Universos Americanos/CSIC, 2009: 209-238.

Belmartino, Susana, et al., Las instituciones de salud en la Argentina, desarrollo y crisis, Buenos Aires, Secretaría de Ciencia y Técnica, 1987.

Belmartino, Susana. et al., Corporación médica y poder en salud, Rosario, Centro de Estudios Sanitarios y Sociales, 1988.

Belmartino, Susana, La atención médica argentina en el siglo XX. Instituciones y procesos, Buenos Aires, Siglo XXI, 2005.

Botana, Natalio y Gallo, Ezequiel, De la República posible a la República verdadera. (1880-1910), Buenos Aires, Ariel, 1997.

Buchbinder, Pablo, Los Quesada. Letras, ciencias y politica en la Argentina, 18501934, Buenos Aires, Edhasa, 2012.

Bunge, Augusto, «El trabajo industrial en Buenos Aires. Informe presentado al Departamento Nacional de Higiene». Anales del Departamento Nacional de Higiene, XI/8 (Buenos Aires, agosto de 1904): 337-364.

Bunge, Augusto, «El trabajo industrial en Buenos Aires. Informe presentado al Departamento Nacional de Higiene», Anales del Departamento Nacional de Higiene, XI/9 (Buenos Aires, septiembre de 1904): 388-410.

Bunge, Augusto, «El trabajo industrial en Buenos Aires. Informe presentado al Departamento Nacional de Higiene», Anales del Departamento Nacional de Higiene, XI/10 (Buenos Aires, octubre de 1904): 435-448.

Bunge, Augusto, «La protección legal de la mujer y el niño obreros», Anales del Departamento Nacional de Higiene, XVI/1 (Buenos Aires, enero de 1909): 1-60.

Bunge, Augusto, «La protección legal de la mujer y el niño obreros», Anales del Departamento Nacional de Higiene, XVI/2 (Buenos Aires, febrero de 1909): 61-114.

Bunge, Augusto, «Las conquistas de la Higiene social», Anales del Departamento Nacional de Higiene, XVI/5 (Buenos Aires, mayo de 1909): 191-242.

Bunge, Augusto, «Las conquistas de la Higiene social», Anales del Departamento Nacional de Higiene, XVI/6 (Buenos Aires, junio-febrero de 1909): 243-271.

Bunge, Augusto, «Las conquistas de la Higiene social», Anales del Departamento Nacional de Higiene, XVI/7 (Buenos Aires, julio de 1909): 289-381.

Bunge, Augusto, «Las conquistas de la Higiene social», Anales del Departamento Nacional de Higiene, XVI/9 (Buenos Aires, septiembre de 1909): 431-472.

Bunge, Augusto, «Las conquistas de la Higiene social», Anales del Departamento Nacional de Higiene, XVI/10 (Buenos Aires, octubre de 1909): 485-599. 
Castel, Robert, La metamorfosis de la Cuestión Social. Una crónica del salariado, Buenos Aires, Paidós, 1997.

Cipolla Carlo, Miasmas and Disease: Public Health and the Environment in the PreIndustrial Age, New Haven, Yale University Press, 1992.

Coni, Emilio, Apuntes científicos (1894-1895). Correspondencias dirigidas a La Prensa e informes enviados a la Comisión de Obras de salubridad de la Capital, Buenos Aires, Imprenta de Pablo Coni e Hijos, 1896.

Coni, Emilio, Progrès de l’higiène dans la République Argentine, París, Librairie J.B Bailliére et Fills, 1887.

Coni, Emilio, Memorias de un médico higienista, Contribución a la historia de la Higiene pública y social argentina. (1869-1917), Buenos Aires, Asociación Médica Argentina, 1918a.

Coni, Emilio, Asistencia y previsión social. Buenos Aires caritativo y previsor, Buenos Aires, E. Spinelli, 1918 b.

Consejo de Redacción, «Consejo de Higiene Pública», Revista Médico-Quirúrgica 1/2 (23 de abril de 1864): 21.

Consejo de Redacción, «Artículos comunicados. El Consejo de Higiene Pública», Revista Médico-Quirúrgica 1/3 (8 de mayo de 1864): 38.

Consejo de Redacción, «El catedrático Puiggari», Revista Médico Quirúrgica 1/11 (8 de septiembre de 1864): 175-177.

Crider, Ernest, Modernization and Human Walfare: The Asistencia Pública and Buenos Aires, 1883-1910, Columbus, Ohio State University, 1976.

Di Liscia María Silvia, Saberes, terapias y prácticas médicas en Argentina (17501910), Madrid, Biblioteca de Historia de América/CSIC, 2002.

Donzelot, Jaques, La invención de lo social. Ensayos sobre la declinación de las pasiones políticas, Buenos Aires, Manantial, 2007

Ferrari, Gustavo y Gallo, Ezequiel (eds.), Argentina del Ochenta al Centenario, Buenos Aires, Sudamericana, 1980.

García Belsunce, Carlos (dir.), Buenos Aires 1800-1830. Salud y delito, Buenos Aires, Emecé, 1977.

González Bernaldo de Quirós, Pilar, «Beneficencia y gobierno en la ciudad de Buenos Aires (1821-1861)», Boletín del Instituto de Historia Argentina y Americana «Dr. Emilio Ravignani», $3^{\mathrm{a}}$ serie/24 (2ºmestre de 2001): 123-157.

González Bernaldo de Quirós Pilar, Civilidad y política en los orígenes de la Nación Argentina, Buenos Aires, Fondo de Cultura Económica, 2007. 
González Leandri, Ricardo, «Caridad y Filantropía en la ciudad de Buenos Aires», Diego Armus, et. al., (eds.) Sectores Populares y vida urbana, Buenos Aires, Flacso, 1984: 251-258.

González Leandri, Ricardo, Curar, persuadir, gobernar. La construcción histórica de la profesión médica en Buenos Aires 1852-1886, Madrid, Biblioteca de Historia de América/CSIC, 1999.

González Leandri, Ricardo, «José María Ramos Mejía, médico, intelectual y funcionario del Estado (1870-1900)», Adriana Álvarez y Adrián Carbonetti, Saberes $y$ prácticas médicas en Argentina. Un recorrido por historias de vida, Mar del Plata, EUDEM, 2008.

González Leandri, Ricardo, González Bernaldo de Quirós, Pilar y Suriano Juan, La Temprana cuestión social. La ciudad de Buenos Aires durante la segunda mitad del siglo XIX, Madrid, Colección América/CSIC, 2010.

González Leandri, Ricardo, «Breve historia del Departamento Nacional de Higiene. Estado, gobernabilidad y autonomía médica en la segunda mitad del siglo XIX», Un Estado con rostro humano. Funcionarios e instituciones estatales en Argentina (desde 1880 hasta la actualidad), Ernesto Bohoslavsky y Germán Soprano (eds.), Buenos Aires, Prometeo/ Universidad de General Sarmiento, 2010: 59-85.

González Leandri, Ricardo, «Itinerarios de la profesión médica y sus saberes de Estado, Buenos Aires, 1850-1910» Mariano Ben Plotkin y Eduardo Zimmermann (comp.), Los saberes del Estado, Buenos Aires, Edhasa, 2012: 125-158.

González Leandri, Ricardo, «Miasmes cosmopolites. Circulation internationale de savoirs et de practiques d'hygiène. Buenos Aires 1850-1870», Liliane Pérez y Pilar Gónzalez Bernaldo de Quirós (dir.), Les savoirs-mondes. Mobilité et circulation des savoirs du Moyen Âge an XXI siècle, Rennes, PUR, 2013 (en prensa).

Gorelik, Adrián, La grilla y el parque. Espacio público y cultura urbana en Buenos Aires, 1887-1936, Bernal, Universidad Nacional de Quilmes, 1998.

Granjel, Mercedes, Pedro Felipe Monlau y la higiene española del siglo XIX, Salamanca, Cátedra de Historia de la Medicina de la Universidad de Salamanca, 1983.

Harrison, Mark, «Disease, diplomacy and international comerce: the origins of international sanitary regulation in the nineteenth century», Journal of Global History, 1 (2006): 197-217.

Huber, Valeska, «The Unification of the Globe by disease? The Internacional Sanitary Conferences on Cholera, 1851-1894», The Historical Journal, 49/2 (2006): 453-476.

Hutchinson, Thomas, «El cólera así llamado en el Rosario» Revista Médico-Quirúrgica, 4/2 (23 de abril de 1867): 22-23. 
Kohn Loncarica, Alfredo, Historia de la inmigración médica en la República Argentina, Tesis de doctorado, Buenos Aires, Facultad de Medicina, Universidad de Buenos Aires, 1981.

Latour, Bruno, The Pasteurization of France, Cambridge Mass., Harvard University Press, 1988.

Lobato, Mirta (ed.), Nueva Historia Argentina, Tomo V: El progreso, la modernización y sus límites (1880-1916), Buenos Aires, Sudamericana, 2000.

Malbrán, Carlos, Apuntes sobre Salud Pública, Buenos Aires, Facultad de Medicina de Buenos Aires, 1931.

Mallo, Pedro, Lecciones de Higiene Privada y Pública, Buenos Aires, Facultad de Medicina de Buenos Aires, 1878.

Moreno, José Luis (comp.), La politica social antes de la política social. Caridad, beneficencia y politica social en Buenos Aires, siglos XVII a XX, Buenos Aires, Prometeo, 2000.

Portela, Eugenio y Soler, Amparo, «La Química española del siglo XIX», Ayer, 7, (1992): 85-107

Prochasson, Christopher, Les Congrès, lieux de l'echange intellectuel, Prochasson, Christopher, Les annès èlectriques, Paris, La Dècouvert, 1991, 1988.

Puiggari, Miguel, «¿Debe la realización de las medidas higiénicas y sanitarias fiarse exclusivamente a las iniciativas de las municipalidades?», Revista Médico-Quirúrgica 2/1 (8 de abril de 1865): 2.

Puiggari Miguel, Lecciones de Química aplicada a la Higiene y a la Administración, Buenos Aires, Imprenta de la Revista, 1863.

Ramos Mejía, José María, Memoria del Departamento Nacional de Higiene, correspondiente a los años 1892, 1893, 1894, 1895, 1896 y 1897, presidencia del Dr. José María Ramos Mejía, Buenos Aires, Imprenta y Encuadernación de «El Correo Español», 1898).

Rawson, Guillermo, Conferencias sobre Higiene Pública, París, Donnamette et Hattu, 1876.

Rawson, Guillermo, Estudio sobre las casas de inquilinato de Buenos Aires, Buenos Aires. Imprenta La Vanguardia, 1942.

Recalde, Héctor, Las epidemias de cólera, (1856-1895), Buenos Aires, Corregidor, 1993.

Recalde, Héctor, La salud de los trabajadores en Buenos Aires (1870-1910). A través de las fuentes médicas, Buenos Aires, Grupo Editor Universitario, 1997.

Repetto, Nicolás, Mi paso por la medicina, Buenos Aires, Santiago Rueda, 1955.

Rodgers, Daniel T., Atlantic Crossings, Cambridge, Massachussets, Harvard University Press, 1998. 
Roncagliolo, Ángel, Cólera. Tesis doctoral, Facultad de Medicina, Buenos Aires, Imprenta La Reforma, 1858.

Rosenberg, Ch., Explaining epidemics and other studies in the History of Medicine, Cambridge, Cambridge University Press, 1999.

Salessi, Jorge, Médicos, maleantes y maricas. Higiene, criminología y homosexualidad en la construcción de la nación argentina (Buenos Aires, 1817-1914), Rosario, Beatriz Viterbo, 1995.

Scobie, James, Buenos Aires, del centro a los barrios, Buenos Aires, Solar/Hachette, 1977.

Scrivener, John H., «Higiene contra el cólera», La Tribuna, 22 de enero de 1868: 2-3.

Stone, Judith F., The Search for Social Peace. Reform legislation in France, 18901914, Albany, State University of New York, 1985.

Suriano, Juan (ed.), La cuestión social en Argentina, 1870-1943, Buenos Aires, Manantial, 2000.

Terán, Oscar, Vida intelectual en el Buenos Aires de fin de siglo, Buenos Aires, Fondo de Cultura Económca, 2000.

Topalov, Christian (dir.), Laboratoires du nouveau siècle, París, Èditions de l'Ècole des Hautes Ètudes en Sciences Sociales, 1999.

Udaondo, Guillermo, «Higiene Administrativa», Anales del Departamento Nacional de Higiene, II/2 (febrero de 1892): 18-27.

Veronelli, Juan Carlos, Medicina, gobierno y sociedad, Buenos Aires, El Coloquio, 1975.

Veronelli, Juan Carlos y Veronelli Correch, Magali, Los orígenes institucionales de la salud pública en Argentina, Tomo 2, Buenos Aires, Organización Panamericana de la Salud, 2004.

Wilde, José Antonio, Compendio de Higiene Pública y Privada al alcance de todos, Buenos Aires, J. A. Bernheim, 1868.

Wilde, Eduardo, Curso de Higiene Pública, Buenos Aires, Imprenta Librería de Mayo. 1885.

Wilde, Eduardo, Congreso internacional de Higiene y Demografía de Bruselas, Anales del Departamento Nacional de Higiene, XI/1 (enero de 1904): 16-17.

Zimmermann, Eduardo Los liberales reformistas en la Argentina, 1890-1916, Buenos Aires: Sudamericana/ Universidad de San Andrés, 1995.

Fecha de recepción: 3/10/12

Fecha de aceptación: 4/1/13 
Internationality, Hygiene and the Social Question in Buenos Aires (1850-1910). Three historic moments.

By looking at three historic moments, this article analyzes aspects about the international circulation of experts, knowledge and institutional models that linked Hygiene to the Social Question in Argentina in the $19^{\text {th }}$ century. In this regard, the great mobility as well as the early and permanent eclecticism through which networks were formed and knowledge became integrated are worth noting.

KeY-words: Social question; State; Hygiene; Internationality; Health; Assistance; Doctors; Argentina. 